\title{
Acute and chronic fluid misdirection syndrome: pathophysiology and treatment
}

\author{
Andrzej Grzybowski ${ }^{1,2} \cdot$ Piotr Kanclerz ${ }^{3}$
}

Received: 7 August 2017 / Revised: 10 October 2017 / Accepted: 16 October 2017 / Published online: 6 November 2017

(C) The Author(s) 2017. This article is an open access publication

\begin{abstract}
Purpose To summarize our current understanding of the specific pathogenic mechanisms of the fluid misdirection syndrome and possible treatment methods.

Methods We used the PubMed web platform to find relevant studies using the following keywords: infusion misdirection syndrome, aqueous misdirection syndrome, ciliary block, ciliovitreal block, capsular block, intraoperative fluid misdirection, subcapsular fluid entrapment, acute intraoperative rock-hard eye syndrome, positive vitreous pressure glaucoma, and malignant glaucoma. Other publications were also considered as a potential source of information when referenced in relevant articles.

Results We collected and analyzed 55 articles dated from 1951 to 2016. Acute intraoperative rock-hard eye syndrome is characterized by a very shallow anterior chamber with the absence of suprachoroidal effusion or hemorrhage and no noticeable pathology of the iris-lens diaphragm. It usually occurs during uneventful phacoemulsification, particularly in hyperopic eyes. The pathophysiology of acute fluid misdirection syndrome is based on inappropriate movement of
\end{abstract}

Andrzej Grzybowski

ae.grzybowski@gmail.com

1 Department of Ophthalmology, University of Warmia and Mazury, Olsztyn, Poland

2 Institute for Research in Ophthalmology, Foundation for Ophthalmology Development, 60-554 Gorczyczewskiego 2/3, Poznan, Poland

3 Department of Ophthalmology, Medical University of Gdańsk, Gdańsk, Poland balanced salt solution via the zonular fibers. This syndrome has also been described as occurring from hours to months, or years, after the initial surgery. The pathophysiology of malignant glaucoma is based on similar mechanisms of ciliolenticular block of aqueous flow leading to the misdirection of aqueous posteriorly into or besides the vitreous gel. Faced with these situations, vitreous decompression is required, preferably with hyaloido-capsulo-iridectomy. In phakic eyes, concomitant cataract extraction would be desirable.

Conclusions We believe both of these clinical conditions should be considered as one syndrome. We suggest the term acute fluid misdirection syndrome for the cascade of events during phacoemulsification surgery. Chronic fluid misdirection syndrome better describes the nature of malignant glaucoma.

Keywords Cataract · Glaucoma, angle-closure · Trabeculectomy $\cdot$ Vitrectomy $\cdot$ Vitreous body

\section{Introduction}

The fluid misdirection syndrome is a serious threat in anterior segment surgery. It is notoriously difficult to treat, and carries a generally uncertain prognosis for long-term control of intraocular pressure. Our understanding of pathophysiology, risk factors, accurate diagnosis, and treatment is hampered by insufficient uniform clinical case clarification. Previously proposed definitions for fluid misdirection syndrome were nonspecific and lacking a comprehensive view. It has been also reported under different names, including infusion misdirection syndrome, aqueous misdirection syndrome, capsular block, ciliovitreal block, ciliary block, intraoperative fluid misdirection, subcapsular fluid entrapment, acute intraoperative rock-hard eye syndrome, positive vitreous pressure 
glaucoma, and malignant glaucoma. Currently, years after the initial description by von Graefe in 1869 [1], we now know much more about this uncommon syndrome, but its characterization still remains incomplete.

This review summarizes our current understanding of the specific pathogenic mechanisms of this rare syndrome and possible treatment methods. Certainly it will assist in identification of risk factors and make it possible to establish an effective treatment of this dangerous syndrome.

\section{Methodology}

We used the PubMed web platform to find prospective or retrospective studies and case reports.

Our keywords have been strictly defined: infusion misdirection syndrome, aqueous misdirection syndrome, ciliary block, ciliovitreal block, capsular block, intraoperative fluid misdirection, subcapsular fluid entrapment, acute intraoperative rock-hard eye syndrome, positive vitreous pressure glaucoma. Other publications were also considered as a potential source of information when referenced in relevant articles.

We selected English language articles and divided our reports into two groups: intraoperative complications (Table 1) and postoperative complications (Table 2). Common risk factors for fluid misdirection syndrome are presented in Table 3.

\section{Results}

We collected and analyzed 55 articles dated from 1951 to 2016. Most of the articles related to intraoperative complications were published since 2010, though the first description by MacKool is from 1993 [4]. As of now, about 20 cases of this syndrome have been described, commonly during uneventful phacoemulsification. The most numerous group of cases was collected by Lau et al. [3] Six eyes were described, which was $1.45 \%$ cases among all phacoemulsification procedures (Table 1).

Articles referring to malignant glaucoma are definitely more numerous, and over 200 cases have been described worldwide. The most abundant was a study described by Al Bin Ali et al. [31] which referred to 69 eyes. Recent studies focus on the optimal surgical approach, as the outcome is still not satisfactory (Table 2).

Common risk factors for fluid misdirection syndrome have been summarized in Table 3.

\section{Discussion}

\section{Mechanisms of acute fluid misdirection syndrome}

The fluid misdirection syndrome is a rare clinical condition characterized by an axially very shallow anterior chamber with the absence of suprachoroidal effusion or hemorrhage and no noticeable pathology of the iris-lens diaphragm. It usually occurs during uneventful phacoemulsification particularly in hyperopic eyes [3]. It is probably underreported; anecdotally, many surgeons admit having experienced it occasionally. The common theme is that it manifests toward the end of irrigation/aspiration (I/A), making the completion of I/ A or the insertion of an intraocular lens impossible because of flat anterior chamber. The accumulation of fluid in the posterior segment engenders increase in posterior pressure, resulting in anterior displacement of the iris-lens diaphragm, axial and peripheral anterior chamber flattening, and secondary angle closure. The severity of this condition was underlined by using the name acute intraoperative rock-hard eye syndrome.

The integrity of the posterior chamber (PC)-anterior hyaloid membrane (AHM) barrier during phacoemulsification has been thoroughly evaluated ex vivo through contrastenhanced magnetic resonance imaging and in the MiyakeApple view on porcine eyes [38, 39]. Prolonged irrigation and deflation/inflation of the anterior chamber are risk factors of AHM detachment, while hydrodissection is associated with an AHM tear [38]. Furthermore, ocular viscosurgical devices (OVD) with higher molecular weight or higher concentration of sodium hyaluronate predisposed the eye to an increased risk of PC-AHM impairment during hydrodissection [39].

In vivo, breaking the $\mathrm{PC}-\mathrm{AHM}$ barrier is extricated by the residual cortical fiber irrigation maneuver. It is excessive irrigation which forces fluids into the PC, thus, the term of infusion misdirection syndrome or intraoperative fluid misdirection has been suggested $[4,6]$. The narrow flow is usually generated by a $27 \mathrm{G}$ straight or curved hydrodissection cannula tip. However, it might take place during I/A with a typical irrigation probe, or phacoemulsification at the time of removing the last remaining nuclear pieces. It might be noticeable that the posterior capsule is flaccid - bulging or billowing forward [4]. Lau et al. [3] claim that higher levels of anterior chamber irrigation might be a risk factor.

Miscellaneous routes for balanced salt solution entering the anterior vitreous or Berger's space have been described. Obviously, a radial extension of capsulorhexis might enable direct access of fluid into the retrocapsular space [4]. In these mild cases, administration of OVD into the anterior chamber might be possible, as well as dry aspiration of retrocapsular fluid [5]. Presumably, if irrigation is performed anteriorly to the anterior capsular flap, fluid could more easily make its way through the zonules. 


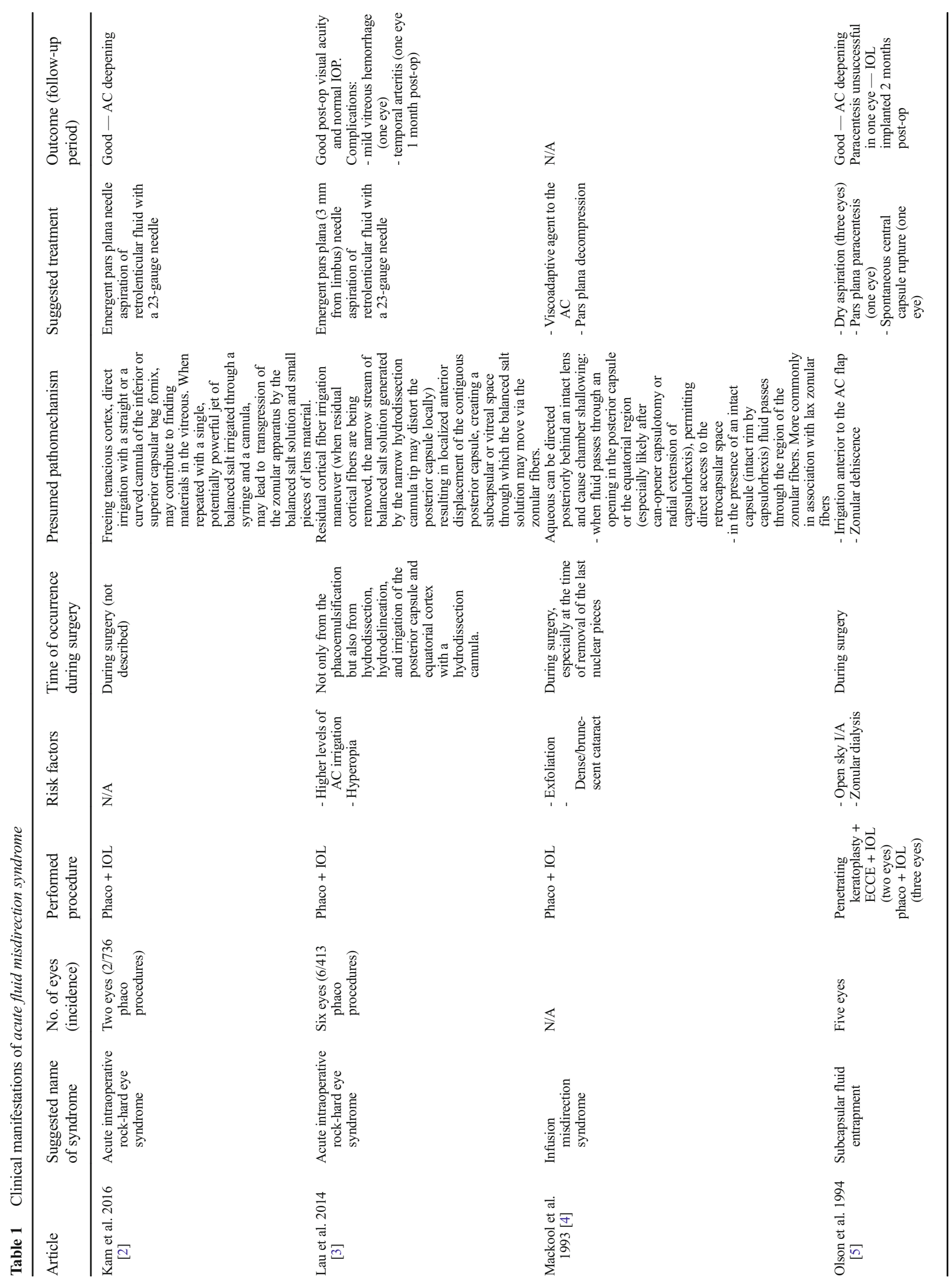




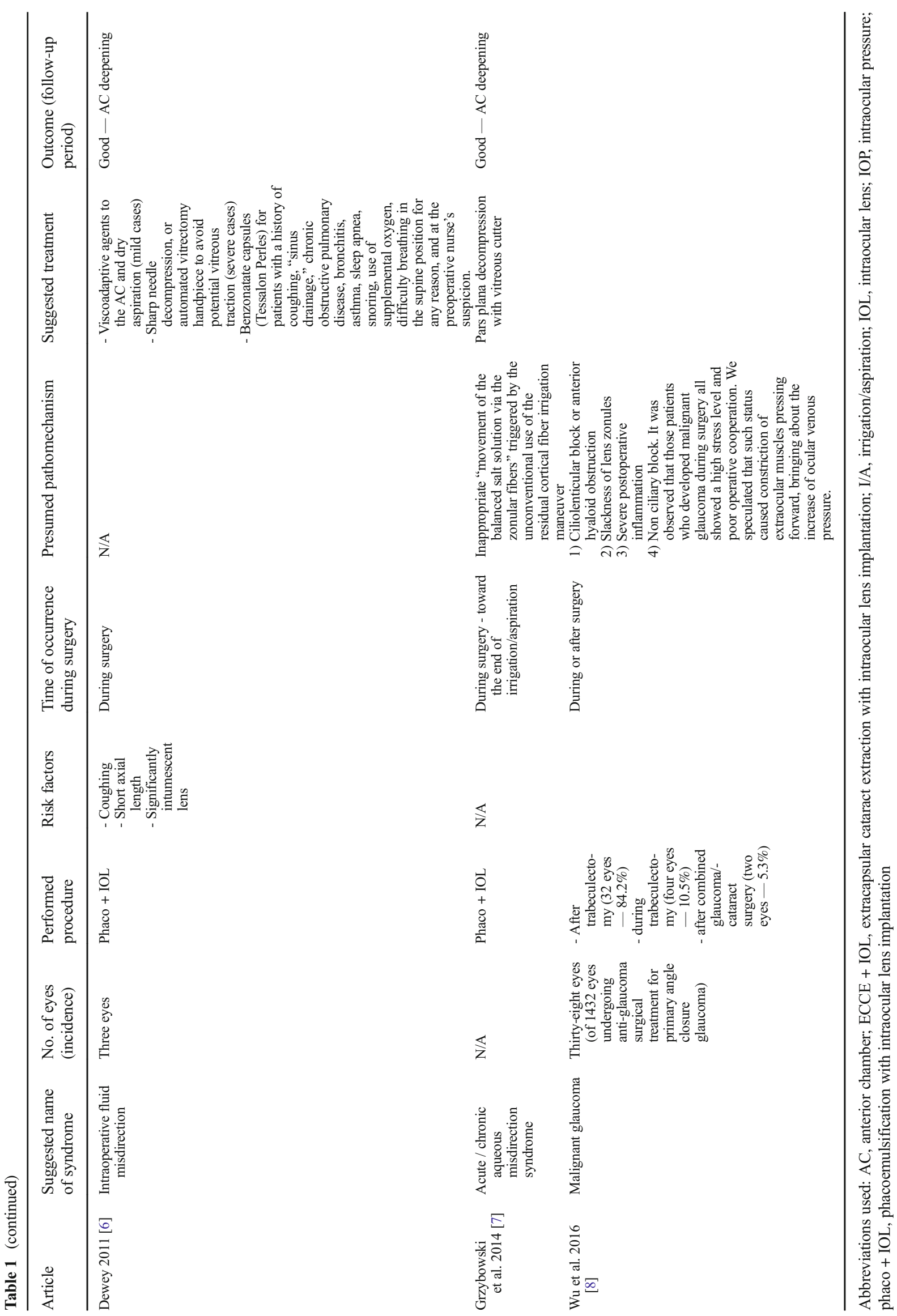




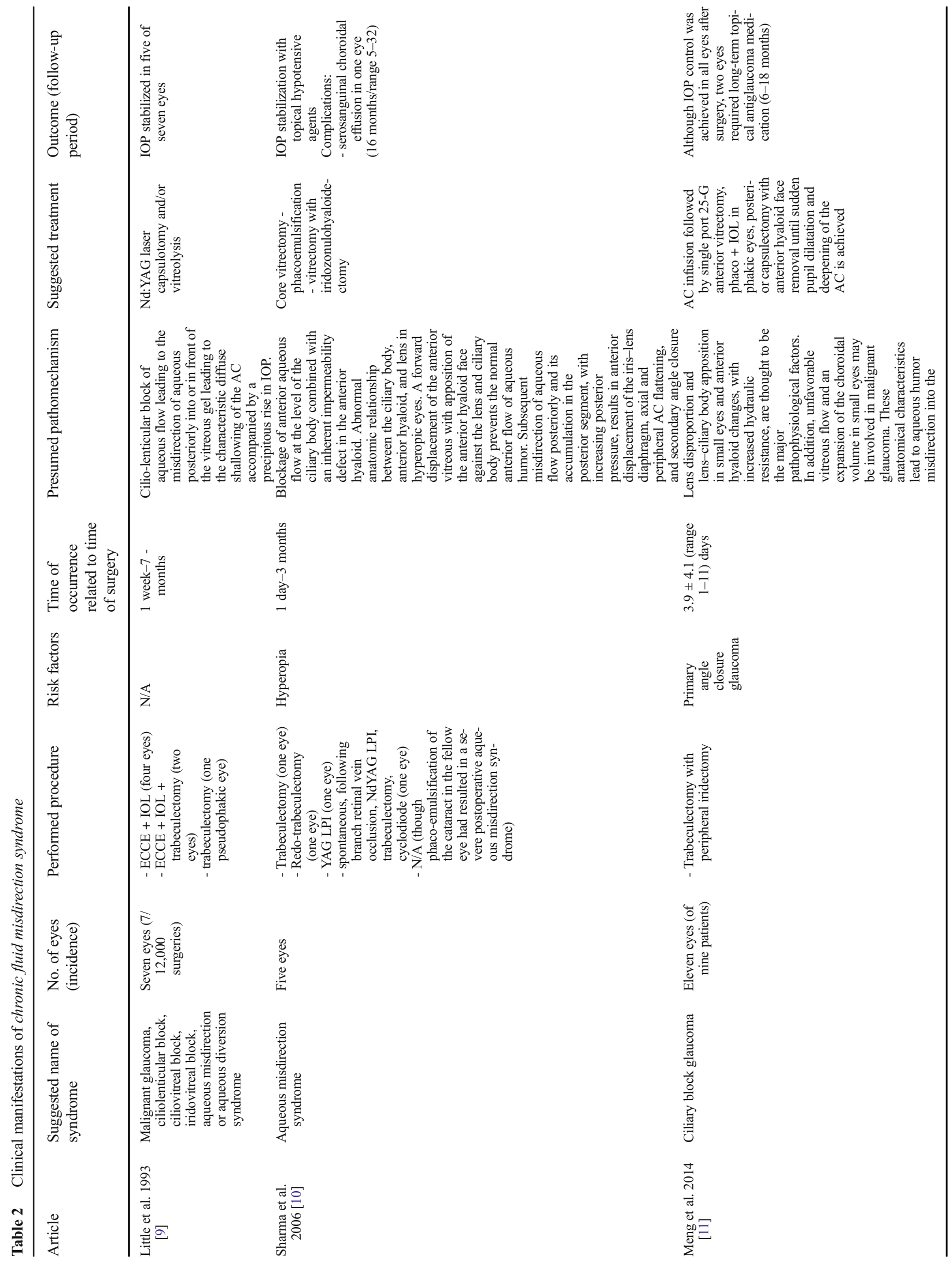




\begin{tabular}{|c|c|c|c|c|}
\hline 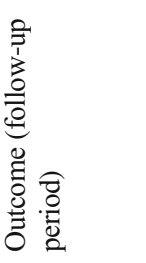 & 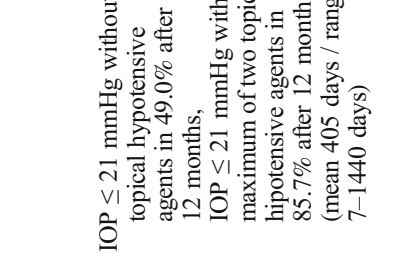 & 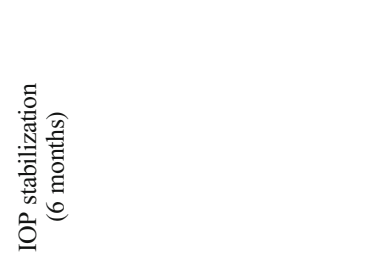 & 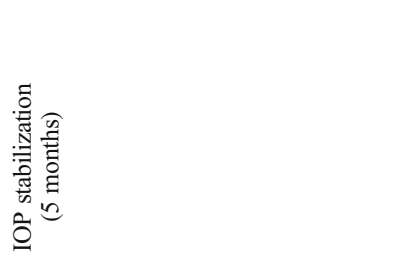 & 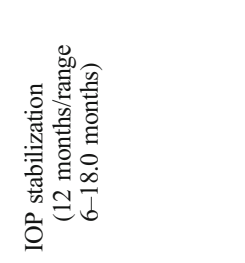 \\
\hline 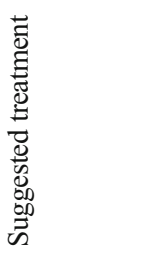 & 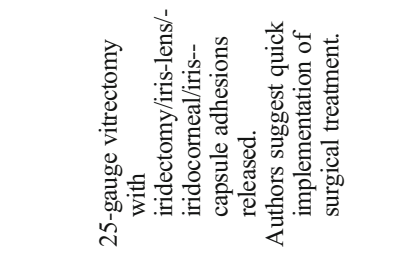 & 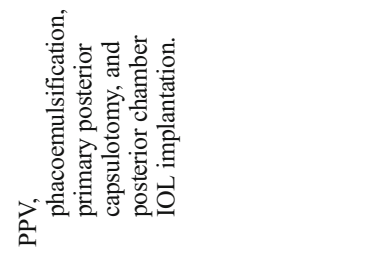 & 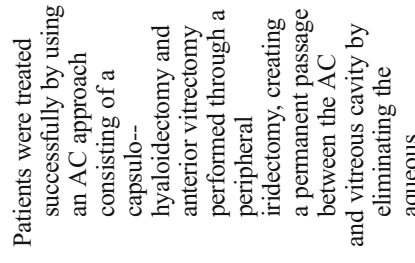 & 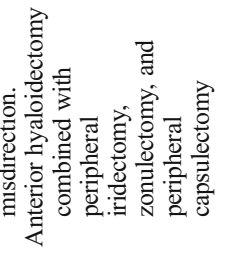 \\
\hline & 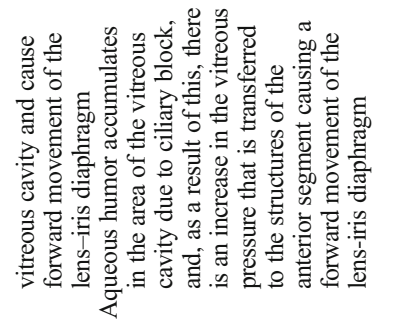 & 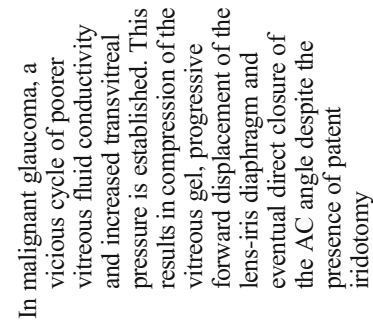 & 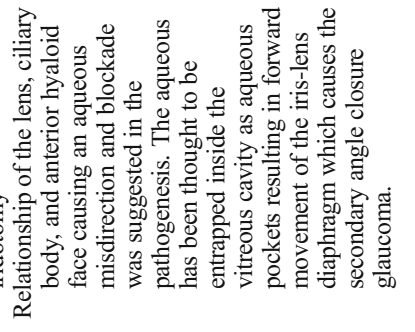 & 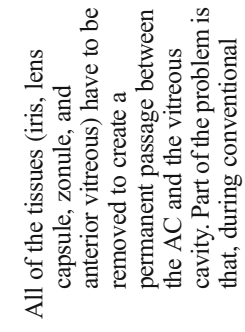 \\
\hline 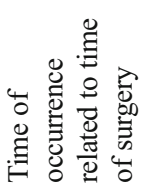 & 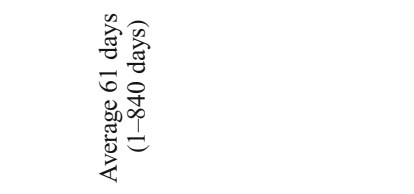 & 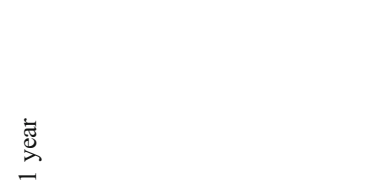 & 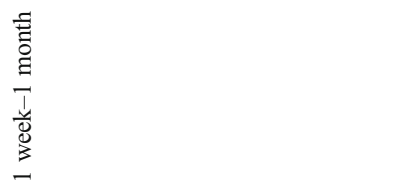 & $\overleftrightarrow{\mathrm{z}}$ \\
\hline & 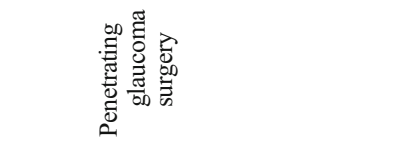 & $\overleftrightarrow{\mathrm{z}}$ & $\frac{k}{z}$ & 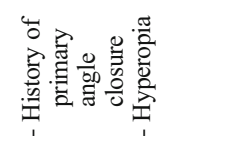 \\
\hline 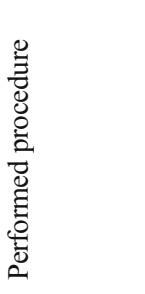 & 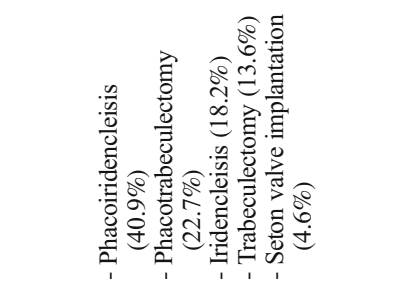 & $\bar{\Xi}$ & 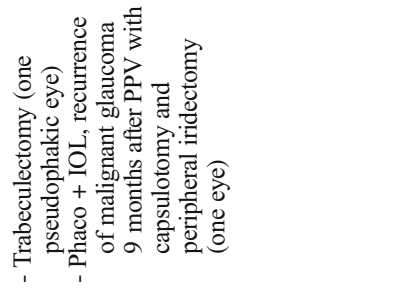 & 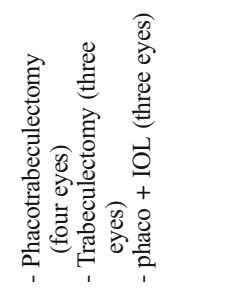 \\
\hline 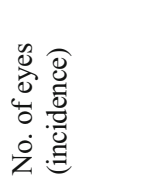 & 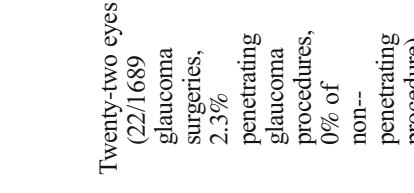 & & 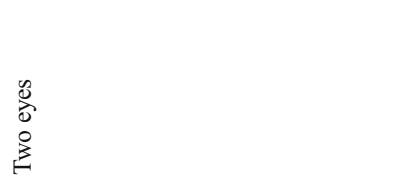 & 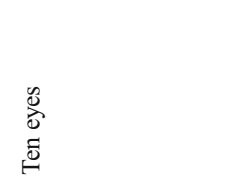 \\
\hline 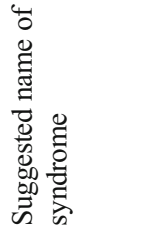 & 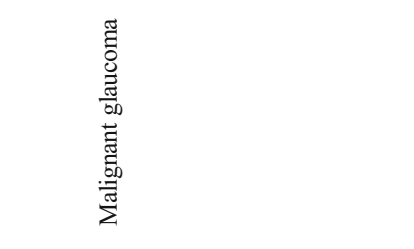 & 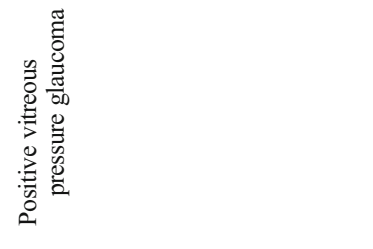 & 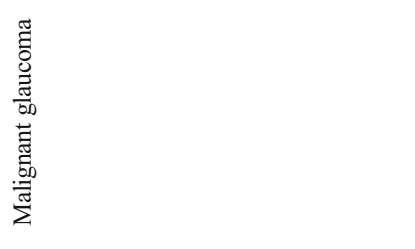 & \\
\hline 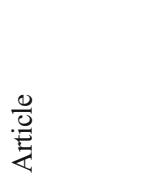 & 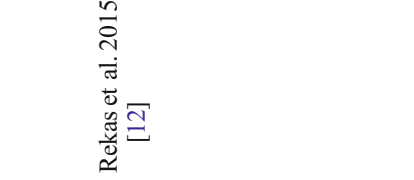 & 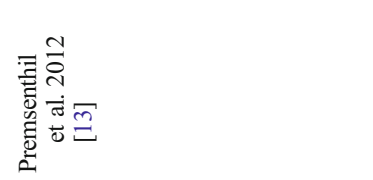 & 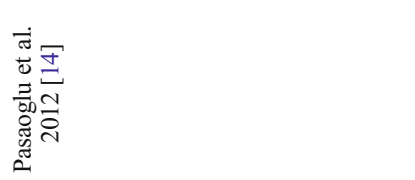 & 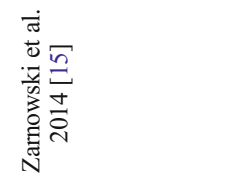 \\
\hline
\end{tabular}




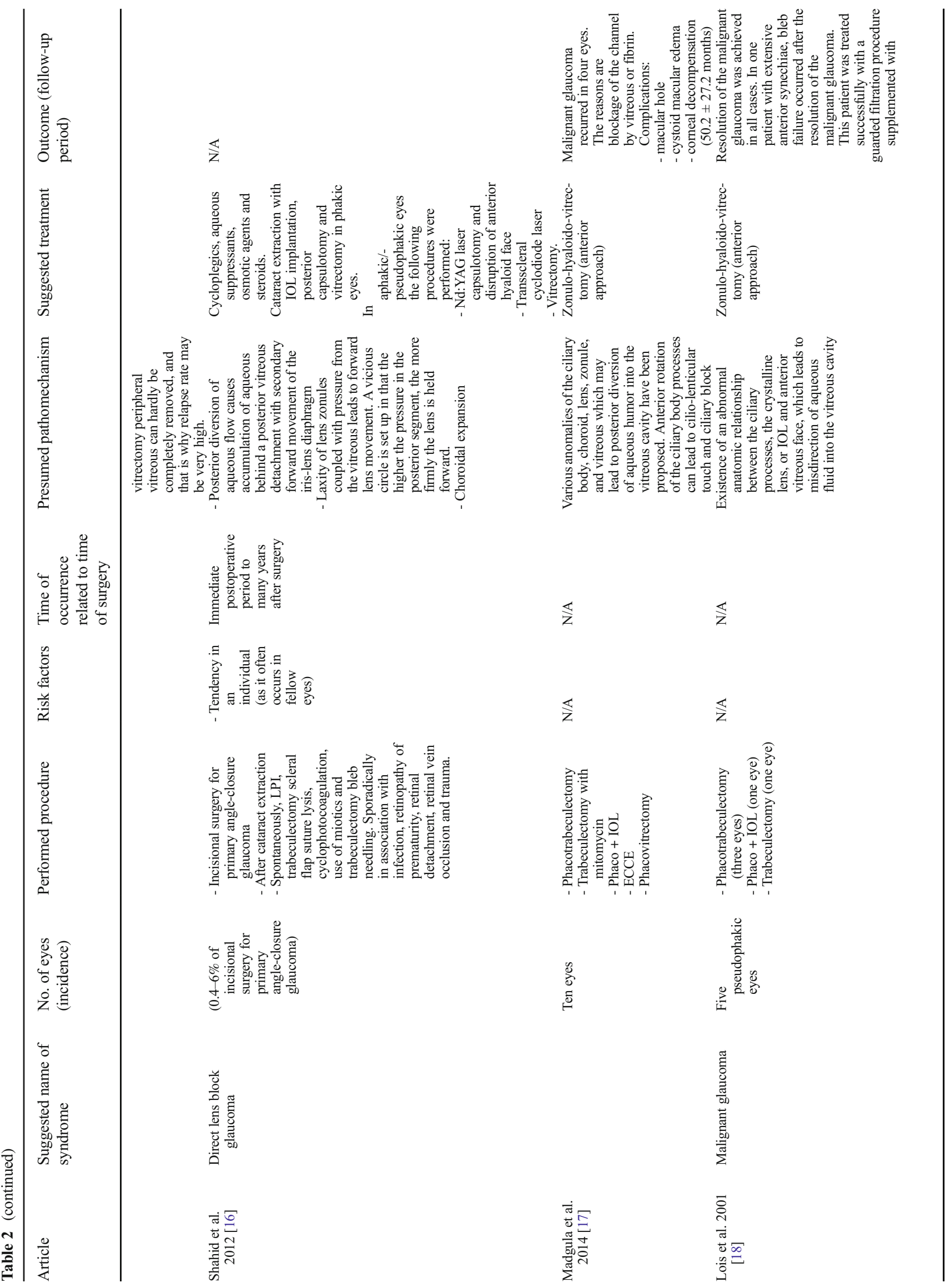




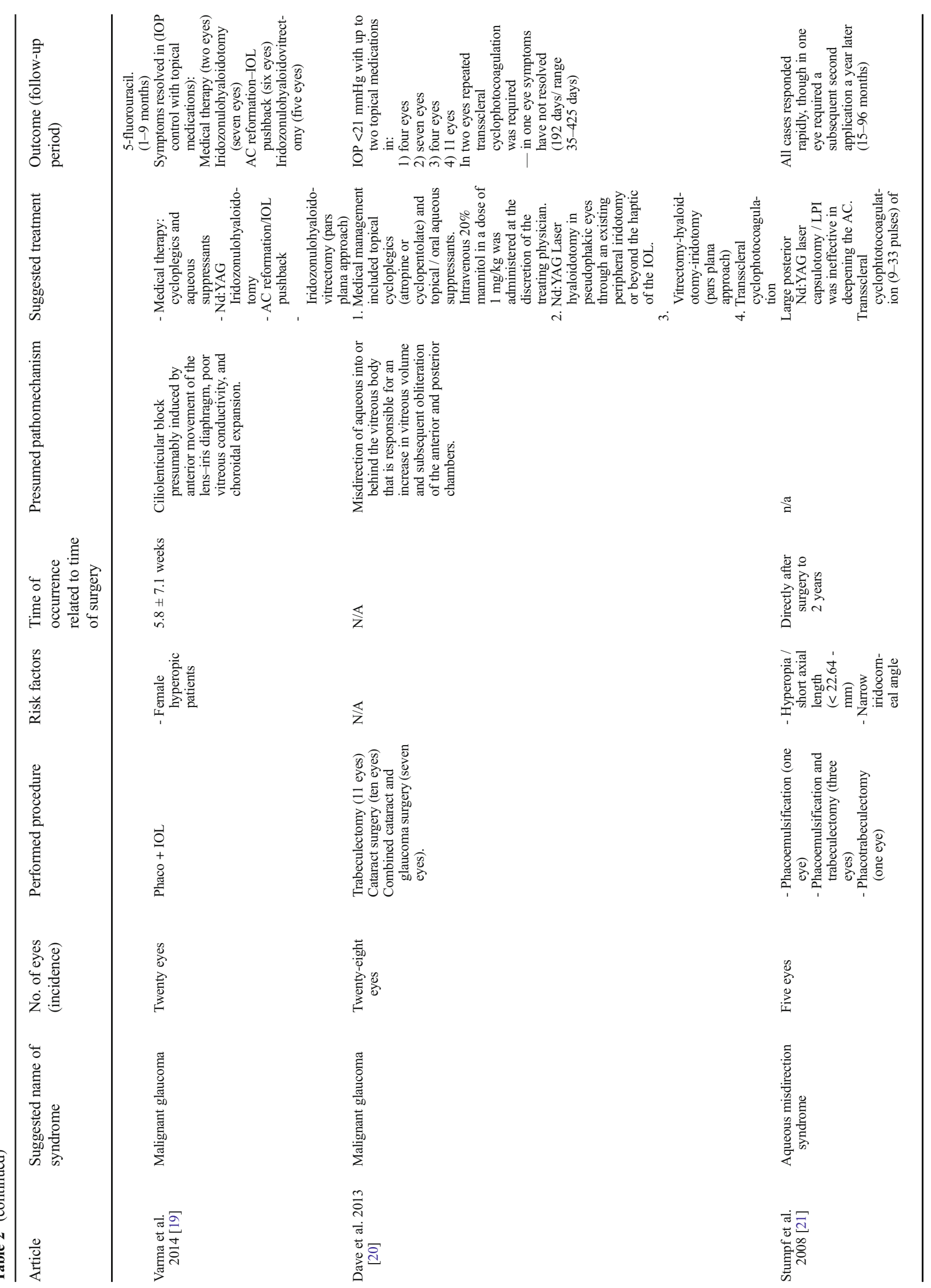




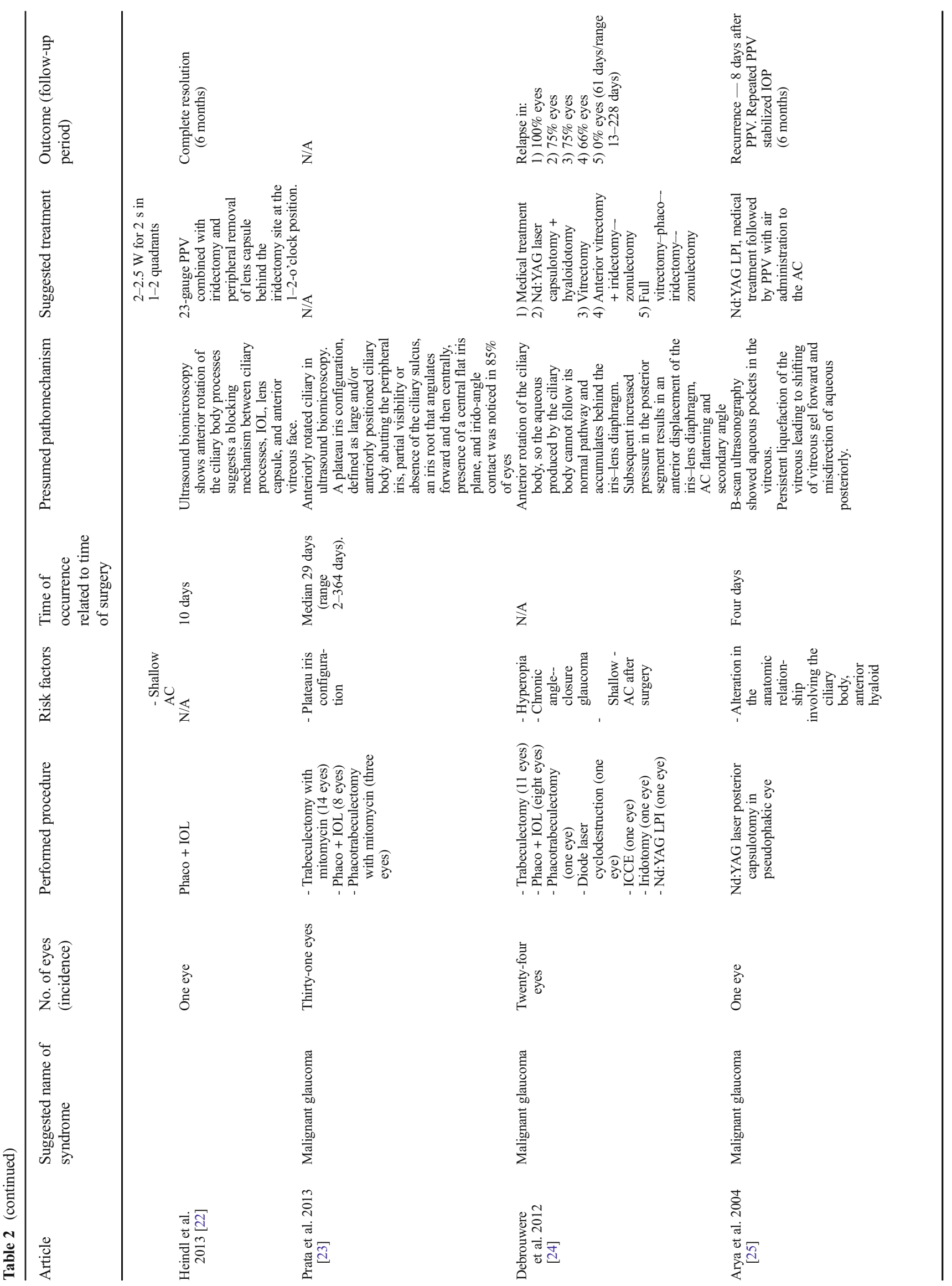




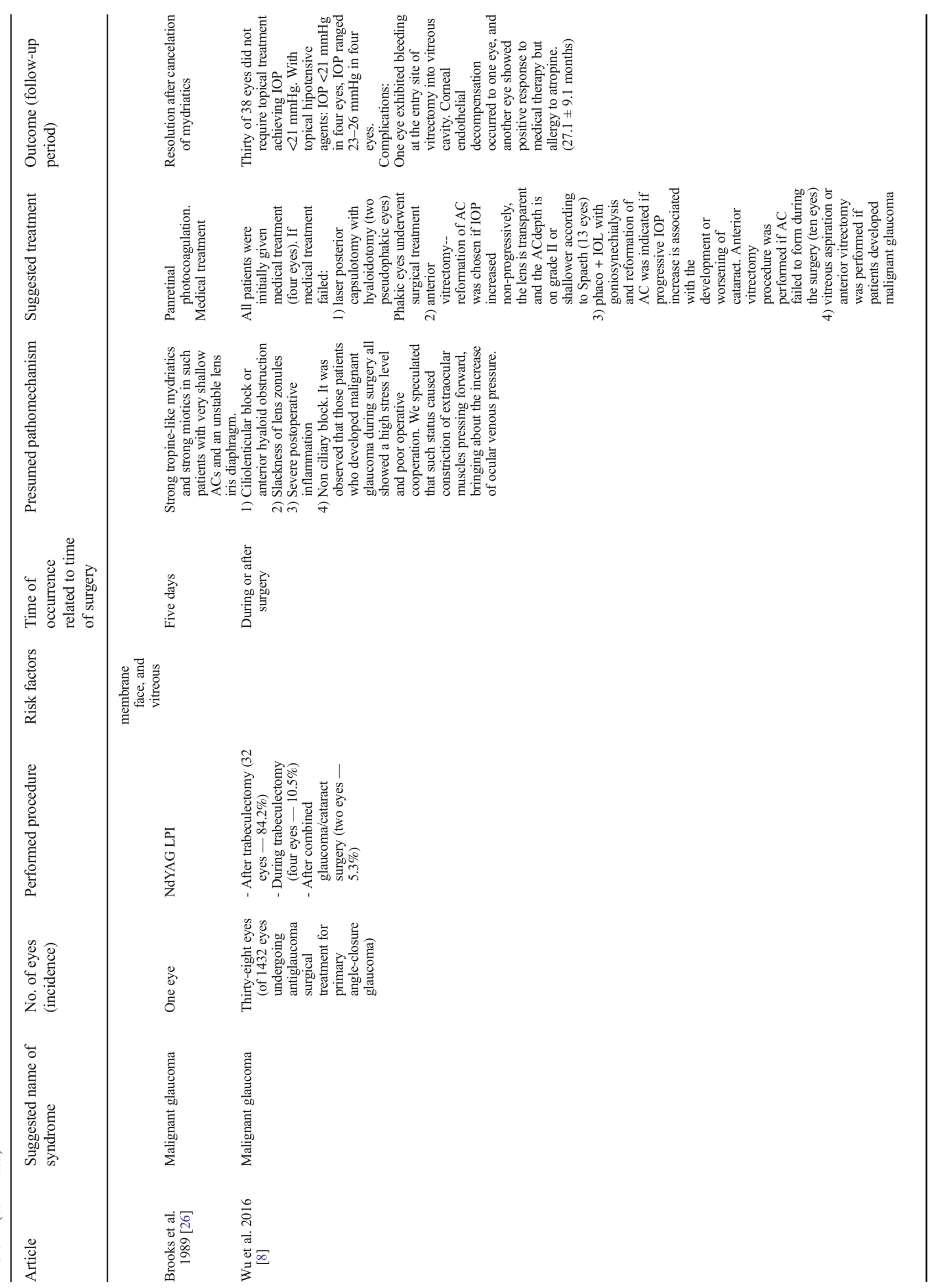




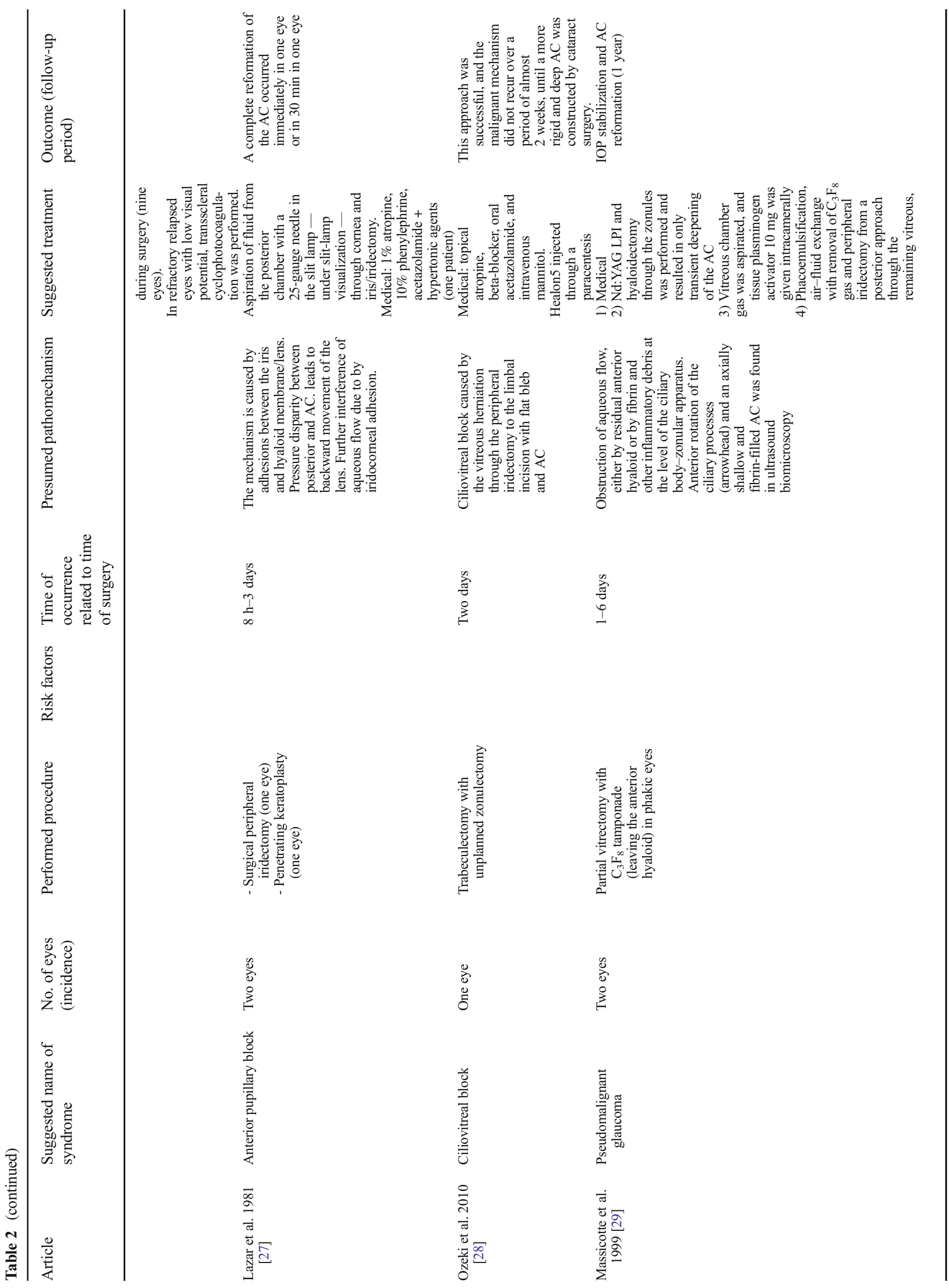




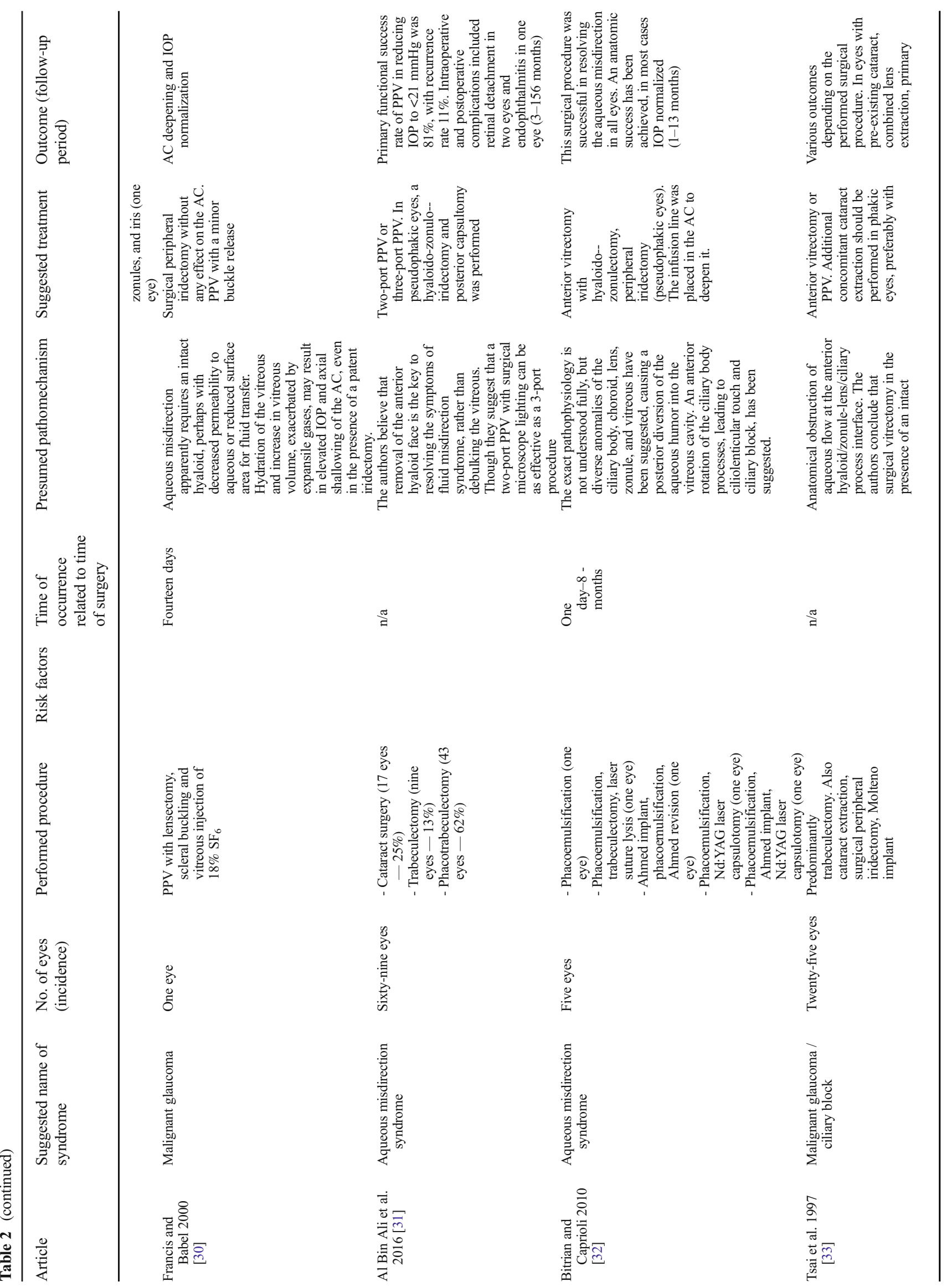




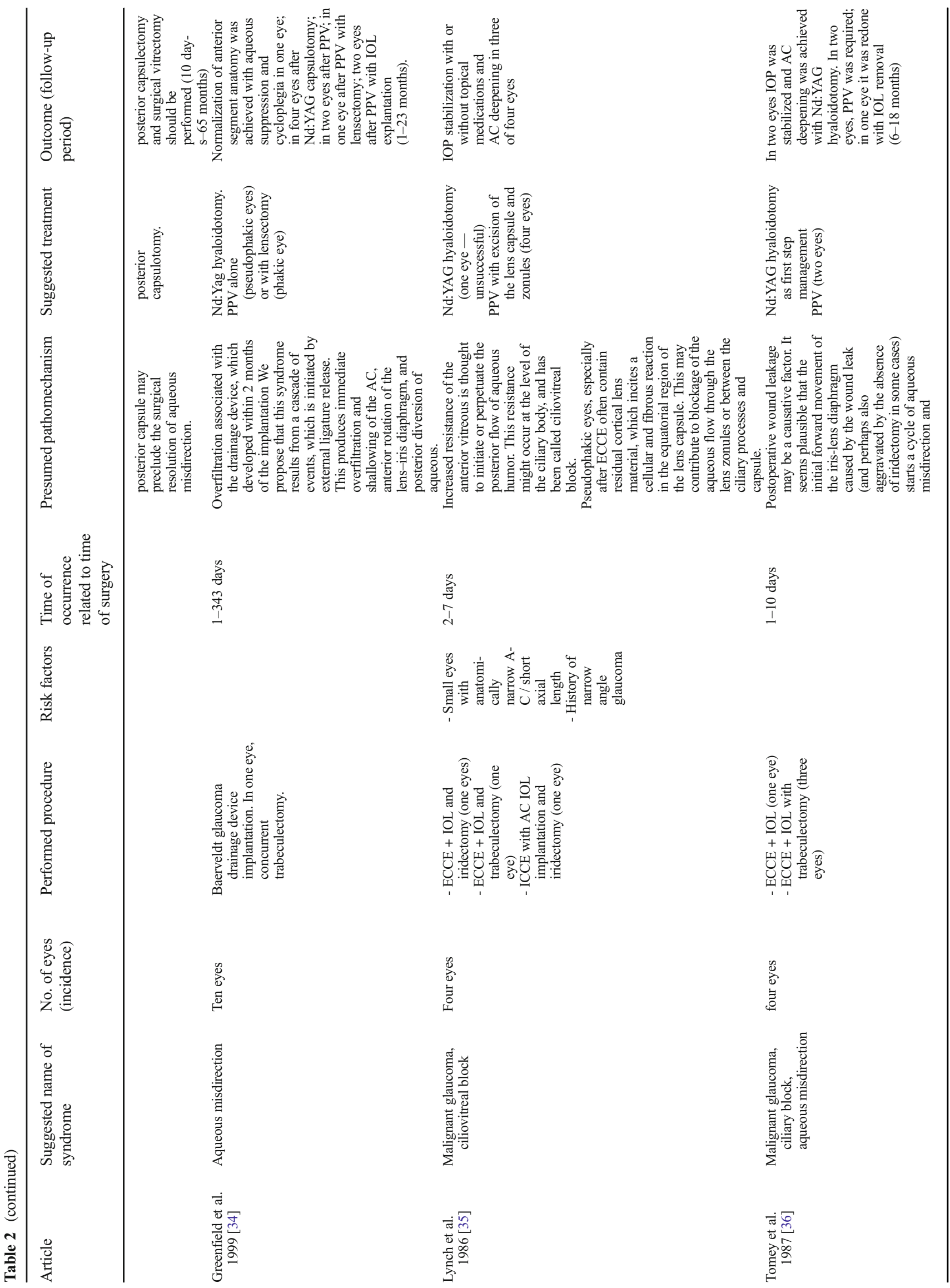




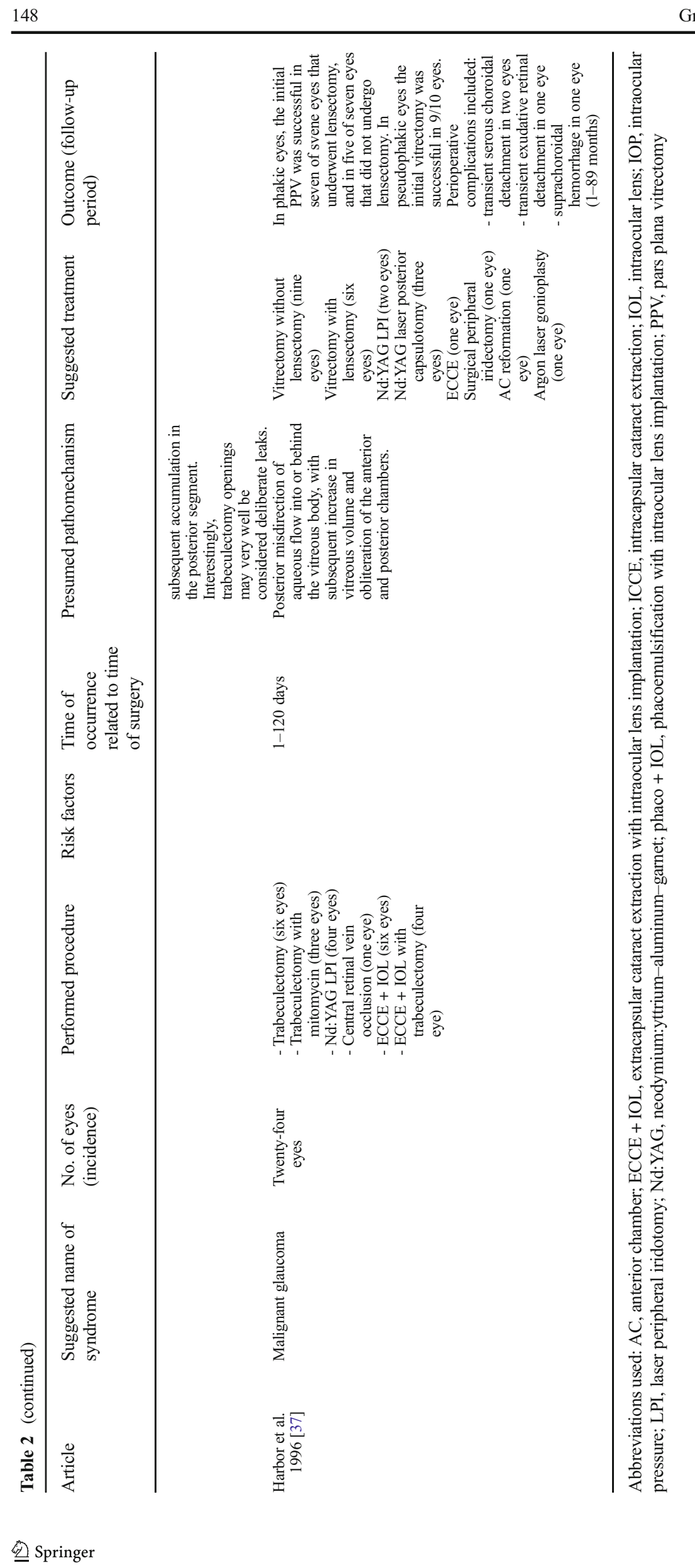


Table 3 Common risk factors for fluid misdirection syndrome

\begin{tabular}{|c|c|c|}
\hline Onset of fluid misdirection & Risk factor & Influence on pathophysiology \\
\hline \multirow[t]{5}{*}{$\begin{array}{l}\text { During phacoemulsification with IOL } \\
\text { implantation or trabeculectomy }\end{array}$} & $\begin{array}{l}\text { - Higher levels of anterior } \\
\text { chamber irrigation [3] }\end{array}$ & $\begin{array}{l}\text { Residual cortical fiber irrigation maneuver (when residual cortical } \\
\text { fibers are being removed, the narrow stream of balanced salt } \\
\text { solution generated by the narrow hydrodissection cannula tip may } \\
\text { distort the posterior capsule locally) resulting in localized anterior } \\
\text { displacement of the contiguous posterior capsule, creating a } \\
\text { subcapsular or vitreal space through which the balanced salt } \\
\text { solution may move via the zonular fibers. }\end{array}$ \\
\hline & $\begin{array}{l}\text { - Coughing [6] or high stress level } \\
\text { with poor intraoperative } \\
\text { cooperation [8] }\end{array}$ & $\begin{array}{l}\text { Increased localized pressure in the eye. Constriction of extraocular } \\
\text { muscles pressing forward, bringing about the increase of ocular } \\
\text { venous pressure. }\end{array}$ \\
\hline & - Hyperopia [3, 6] & $\begin{array}{l}\text { Small hyperopic eyes with shallow anterior chamber, leading to a } \\
\text { decrease of surgical space. }\end{array}$ \\
\hline & - Intumescent cataract $[4,6]$ & $\begin{array}{l}\text { Posterior capsule flaccidity might result in bulging or billowing } \\
\text { forward }\end{array}$ \\
\hline & - Pseudoexfoliation [4] & $\begin{array}{l}\text { Lax zonular fibers might facilitate the fluid passage through the } \\
\text { region of the zonular fibers. }\end{array}$ \\
\hline $\begin{array}{l}\text { During penetrating keratoplasty with } \\
\text { extracapsular cataract extraction and IOL } \\
\text { implantation }\end{array}$ & $\begin{array}{l}\text { - Open sky irrigation/aspiration } \\
\text { [5]) }\end{array}$ & Irrigation under the iris, anteriorly to the anterior capsule \\
\hline \multirow[t]{4}{*}{$\begin{array}{l}\text { Following phacoemulsification with IOL } \\
\text { implantation, trabeculectomy or } \\
\text { phacotrabeculectomy }\end{array}$} & - Hyperopia $[10,19,21]$ & $\begin{array}{l}\text { Abnormal anatomic relationship between the ciliary body, anterior } \\
\text { hyaloid, and lens in hyperopic eyes. Anterior movement of the } \\
\text { lens-iris diaphragm accompanied with poor vitreous conductivity } \\
\text { and choroidal expansion. }\end{array}$ \\
\hline & $\begin{array}{l}\text { - History of angle closure } \\
\quad[11,15,24,35]\end{array}$ & $\begin{array}{l}\text { Increased resistance of the anterior vitreous initiates the posterior flow } \\
\text { of aqueous humor. }\end{array}$ \\
\hline & - Plateau iris configuration [23] & $\begin{array}{l}\text { Anterior rotation of the ciliary body, so the aqueous produced by the } \\
\text { ciliary body cannot follow its normal pathway and accumulates } \\
\text { behind the iris-lens diaphragm. }\end{array}$ \\
\hline & $\begin{array}{l}\text { - Shallow anterior chamber } \\
\text { after surgery [21] }\end{array}$ & $\begin{array}{l}\text { A forward displacement of the anterior vitreous with apposition of the } \\
\text { anterior hyaloid face against the lens and ciliary body prevents the } \\
\text { normal anterior flow of aqueous humor. }\end{array}$ \\
\hline
\end{tabular}

Abbreviations used: IOL, intraocular lens

In intact capsules, the zonular dehiscence may enable fluid to flow in an unusual pattern, facilitating its entrapment in the PC. This elucidates why this syndrome is commonly associated with lax zonular fibers, i.e., in exfoliation, dense/ brunescent cataracts, or spherophakia. However, it can develop in the absence of any clinically detectable zonular fiber weakness or disruption [4], and might be associated with spontaneous $\mathrm{PC} /$ vitreous pressure elevation induced by intraoperative coughing [6]. As habitually shallowing of the anterior chamber is irreversible, Olson et al. defined the term subcapsular fluid entrapment.

\section{Optimal treatment for acute fluid misdirection syndrome}

Faced with these situations, pars plana decompression is required. Exceptionally spontaneous posterior capsule rupture and liberation of the entrapped fluid has been described [5]. Prior to performing a posterior decompression, the surgeon must be definitely certain that there is no evidence of choroidal effusion or hemorrhage. The decompression might be done by puncture with a straight needle $3 \mathrm{~mm}$ from the rim and then aspiration of retrolenticular fluid [3-5]. Vitreous traction might be a concern when performing this procedure. Furthermore, the treatment has not always been described as successful [5].

Hence it would be preferable to use a small-gauge trocar/ cannula vitrectomy cutter (23-, 25-, or 27-gauge) [7]. The incision in the pars plana should be made after displacing the conjunctiva and then fashioning a beveled incision, as is modern practice for pars plana entries. The cutter can then remove retrocapsular fluid using a high cut rate.

\section{Mechanisms of chronic fluid misdirection syndrome}

This syndrome has also been described as occurring from hours to months, or years, after the initial surgery [9]. Malignant glaucoma is a recalcitrant and potentially devastating secondary angle-closure glaucoma. In 1869, von Graefe described a rare postoperative complication characterized by flattening of the anterior chamber and elevated 
intraocular pressure (IOP). As a result of its poor response to conventional treatment, it was called malignant glaucoma [1]. The term was further justified by the devastating effect of using pilocarpine as an attempted treatment for this condition. It is recognized to comprise the diagnostic triad of a diffusely flat anterior chamber, high intraocular pressure, and aqueous pooling that is sometimes visible in or in front of the anterior vitreous. This occurs despite the existence of a patent iridotomy or iridectomy (Fig. 1). It is best known following trabeculectomy, but has been reported following a wide variety of anterior segment procedures, including cataract extraction or implantation of several glaucoma drainage devices, i.e., Ahmed, Molteno, Baerveldt [32-34]. Furthermore, it can occur subsequent to laser

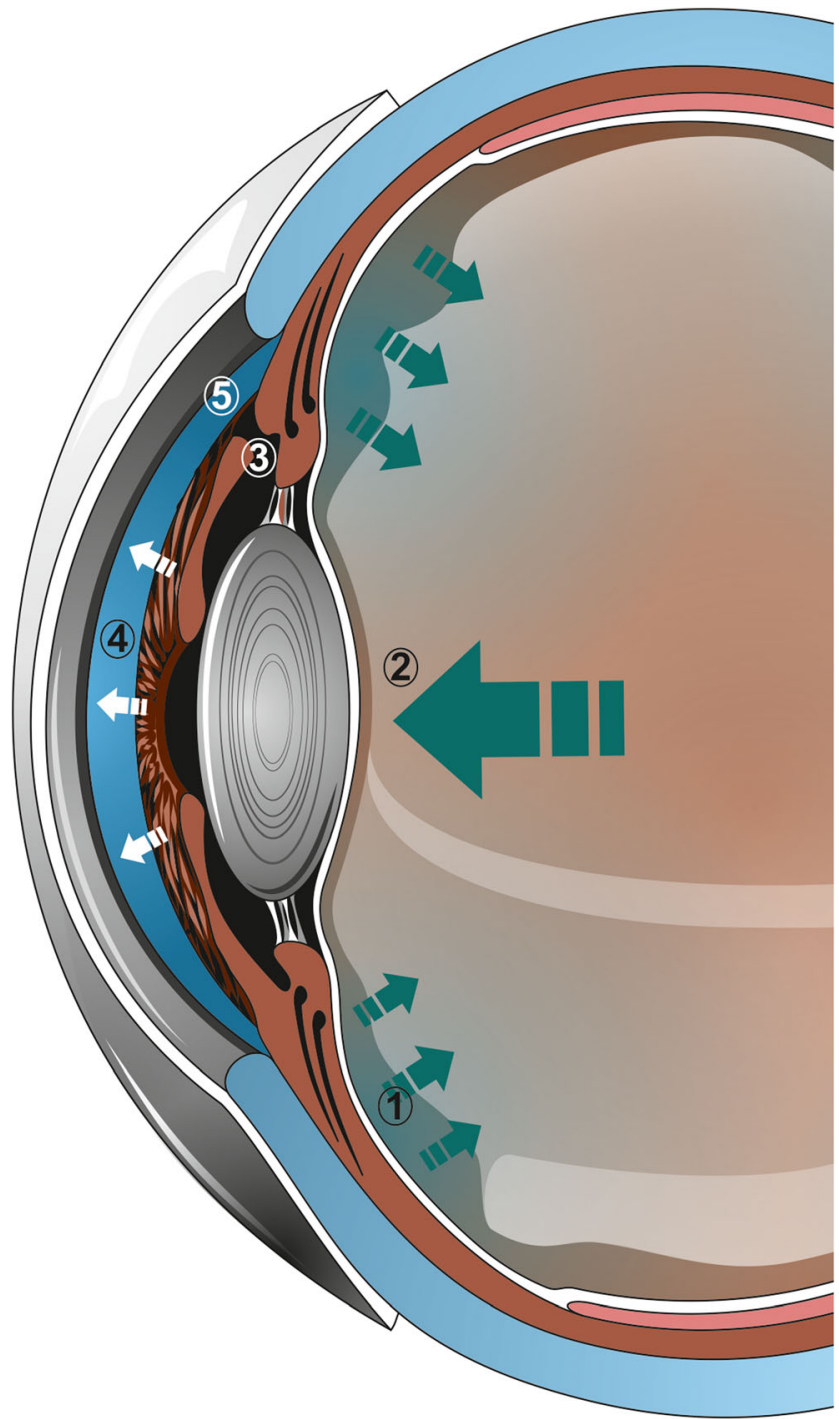

Fig. 1 Mechanism of chronic fluid misdirection syndrome. The aqueous humor secreted by the ciliary epithelium is not directed to the anterior chamber (1), which leads to positive vitreous pressure (2). This occurs despite the existence of a patent iridotomy or iridectomy (3). Subsequently a diffusely flat anterior chamber (4) and angle closure (5) can be observed with precipitous rise in intraocular pressure peripheral iridotomy, surgical peripheral iridectomy, c a psulotomy, cyclophotocoagulation, phacotrabeculectomy, trabeculectomy scleral flap suture lysis, trabeculectomy bleb needling, or initiation of topical miotic $[5,10,12,24,40]$. Although pars plana vitrectomy is an effective treatment for malignant glaucoma, it does not rule out the development of this syndrome postoperatively [29, 30]. Furthermore cases of malignant glaucoma have been described following vitrectomy, particularly in phakic eyes [29, 30, 41]. In a study conducted by Matlach et al., the IOP in malignant glaucoma following trabeculectomy was slightly lower than after other procedures; furthermore, this group of patients required fewer topical IOP-lowering medications [42].

There is an anatomical predisposition for malignant glaucoma. Most patients have chronic angle-closure glaucoma or an anatomically narrow filtration angle. In other studies, plateau iris configuration and hyperopia have been defined as risk factors $[10,15,23,24]$. Additionally, anterior rotation of the ciliary body processes in ultrasound biomicroscopy might be significant for averting aqueous fluid flow [22]. Malignant glaucoma is indeed more common in women than in men. In women, the location of the lens is more forward than that of the lens in men, resulting in not only a $4 \%$ shallower anterior chamber but also a narrower space between the lens equator and ciliary body. Therefore, women are more prone to developing a misdirection of the aqueous flow [43]. Chandler et al. proposed that laxity of lens zonules coupled with pressure from the vitreous leads to forward lens movement [44]. In spherophakia, zonular dehiscence might be accompanied by increased lens thickness, hence facilitating anterior chamber shallowing [45].

Due to the fact that the aqueous humor secreted by the ciliary epithelium is not directed to the anterior chamber, the term aqueous misdirection syndrome has been proposed [10]. It might accumulate in the vitreous or adjacent to it in Berger's space. A forward displacement of the anterior vitreous with apposition of the anterior hyaloid face against the lens and ciliary body might be significant in averting the flow of aqueous humor [9]. Furthermore, the aqueous might become entrapped inside the vitreous cavity as "aqueous pockets" $[14,40]$. Other studies suggest that anterior vitreous and anterior hyaloid face condensation result in reduced permeability to the aqueous. With that, vitreous detachment would facilitate trapping fluid in the posterior segment [10]. Little et al. [9] suggest that aqueous might accumulate in front of the anterior vitreous, and its pooling can be sometimes visible.

The misdirection of aqueous leads to increasing the pressure of the posterior chamber vitreous (positive vitreous pressure glaucoma) [13] and anterior displacement of the lens-iris diaphragm. Consequently, a characteristic diffuse shallowing of the anterior chamber can be observed, with subsequent angle closure and rise in intraocular pressure [10]. The 
aqueous misdirection is inevitable - Shaffer and Hoskins postulated a valve-like mechanism by which aqueous humor was "misdirected" posteriorly [46]. A vicious circle is set up, in that the higher the pressure in the posterior segment, the more firmly the lens is held forward $[13,16]$.

Quigley et al. suggest that rather than a one-way ball valve mechanism, choroidal expansion could play a significant role in malignant glaucoma. In an average human eye, the vitreous volume is approximately $5000 \mu \mathrm{l}$ and the choroidal volume is about $480 \mu \mathrm{l}$, while the anterior chamber volume is $150 \mu \mathrm{l}$ [47]. From solid geometry and ocular dimensions, choroidal expansion by $20 \%$ occupies a volume $100 \mu \mathrm{l}$, equal to the volume of the anterior chamber [48]. A 100- $\mu \mathrm{m}$ uniform choroidal expansion could increase IOP to $60 \mathrm{mmHg}$ [47]. With the expansion of the choroid, the absolute pressure in each compartment of the eye increases. This induces a volume loss from the anterior chamber, with increased aqueous outflow. As the pressure in the posterior globe is higher than in the anterior chamber, an anterior movement of the vitreous, carrying the lens and iris with it, leads to further anterior chamber narrowing. This additionally decreases the outflow, causing a vicious circle.

\section{Treatment strategies for chronic fluid misdirection syndrome}

Malignant glaucoma would be more likely to occur in eyes with higher than normal resistance to vitreous fluid flow. Normal vitreous does not limit the free passage of water, and its fluid conductivity decreases under an increased pressure differential [49]. If the transvitreous flow is limited and insufficient to equalize the difference in pressure between the vitreous chamber and anterior chamber, the vitreous compresses more. This further decreases its fluid conductivity. The surface through which aqueous exits the vitreous is limited by the ciliary body at its perimeter and apposition of vitreous to the lens centrally, forming a doughnut-shaped zone. The compression of vitreous and its anterior movement gradually limits the diffusional area. Furthermore in hyperopic eyes with smaller axial length and relatively larger lens the doughnut-shaped zone would be only half as large as normal-sized eyes [48].

Tomey et al. [36] claim, that postoperative wound leakage following cataract surgery may be a causative factor for malignant glaucoma. It seems probable that the initial forward movement of the iris-lens diaphragm caused by the wound leak starts a cycle of aqueous misdirection and subsequent accumulation in the posterior segment. This might be aggravated by the absence of iridectomy in some cases. Interestingly, filtration surgery with increased aqueous outflow might also be considered as a triggering factor.

The treatment strategies for malignant glaucoma are typically aimed at managing IOP and restoring normal anterior segment anatomy. Medical therapy is reported to be successful. Cycloplegics draw the lens-iris complex posteriorly, widen the ciliary body diameter, increasing forward diffusional area for fluid to leave the posterior vitreous cavity. Osmotic agents remove fluid from the eye, and aqueous suppressants decrease its production. Although medical treatment can help partially or completely stabilize malignant glaucoma, they do not address the underlying pressure imbalance; thus the relapse rate is described to be as high as $100 \%$ [24].

In aphakic and pseudophakic eyes neodymium:yttriumaluminum-garnet (Nd:YAG) laser iridotomy with anterior hyaloidotomy and posterior capsulotomy (all through the same location) might stabilize the intraocular pressure [9]. This approach leads to relieving aqueous that might be entrapped within the vitreous. Ultrasound biomicroscopic imaging revealed that anterior rotation of the ciliary body and anterior chamber shallowing normalize after rupture of the anterior hyaloid face [50]. However, the procedure might have a short-term effect with a high recurrence rate of $75 \%$, presumably because the primary mechanism of misdirection is not counteracted, allowing new aqueous to accumulate in the vitreous cavity [24]. Furthermore, there might be an inflammatory reaction in blocking the flow of aqueous across the zonules or between the lens capsule and ciliary processes, especially in eyes with residual cortical lens material [35]. Some authors underline the efficacy of transscleral cyclophotocoagulation $[20,21]$. The coagulative necrosis and shrinkage of the ciliary processes disrupts the ciliary-hyaloid interface. In addition to decreasing aqueous production, this disruption may subsequently allow normal aqueous flow and mechanical posterior rotation of the ciliary body. This method needs to be considered, although some authors prefer to use a non-destructive intervention, especially in a patients with well-seeing eyes [20]. Importantly, this approach does not complicate a subsequent surgical procedure [21]. It is suggested that although cyclophotocoagulation helps to achieve resolution in most eyes, performing vitrectomy with hyaloidotomy and iridectomy with implantation of a glaucoma drainage device in eyes in which laser hyaloidotomy failed could be a better option [20].

Thus, in several cases surgical treatment might be necessary. Certain authors stress that the greatest chance for permanent success is related to quick implementation of surgical treatment [51]. Furthermore, eyes with higher IOP and shorter axial length might be more likely to have a poor prognosis [52]. The fundamentals of the treatment are that evacuation of vitreous and aqueous humor from the vitreous cavity and establishment of communication with the anterior chamber helps to stop the vicious mechanism that eventually leads to increased IOP. Pars plana vitrectomy prevents aqueous accumulation inside the vitreous cavity, and it has been reported to be the treatment of choice for pseudophakic malignant glaucoma. Some authors suggest that a total vitrectomy, rather 
than partial removal of the anterior vitreous, is favorable [15]. However, this may not be enough to disrupt the cycle of malignant glaucoma, as it is postulated that all of the tissues (iris, lens capsule, zonule, and anterior vitreous) have to be removed to create a permanent passage between the anterior chamber and the vitreous cavity [10, 12, 20, 24]. (Fig. 2) Furthermore, Debrouwere et al. [24] emphasized that total vitrectomy was not effective in $66 \%$ of their patients unless an zonulectomy was added to the procedure. Part of the problem is that during conventional vitrectomy peripheral vitreous can hardly be completely removed, and that is why relapse rate may be very high [15]. Only total vitrectomy combined with zonulectomy, iridectomy, and capsulectomy has been described to be effective in $100 \%$ on larger groups of patients $[12,24]$. In postoperative follow-up, it is important to maintain patency of newly created passages by using an Nd:YAG laser [12]. An alternative surgical treatment for pseudophakic malignant glaucoma suggested by anterior segment surgeons is zonulo-hyaloido-vitrectomy $[14,15,17,18]$. In this procedure, the anterior vitrectomy is performed from the anterior

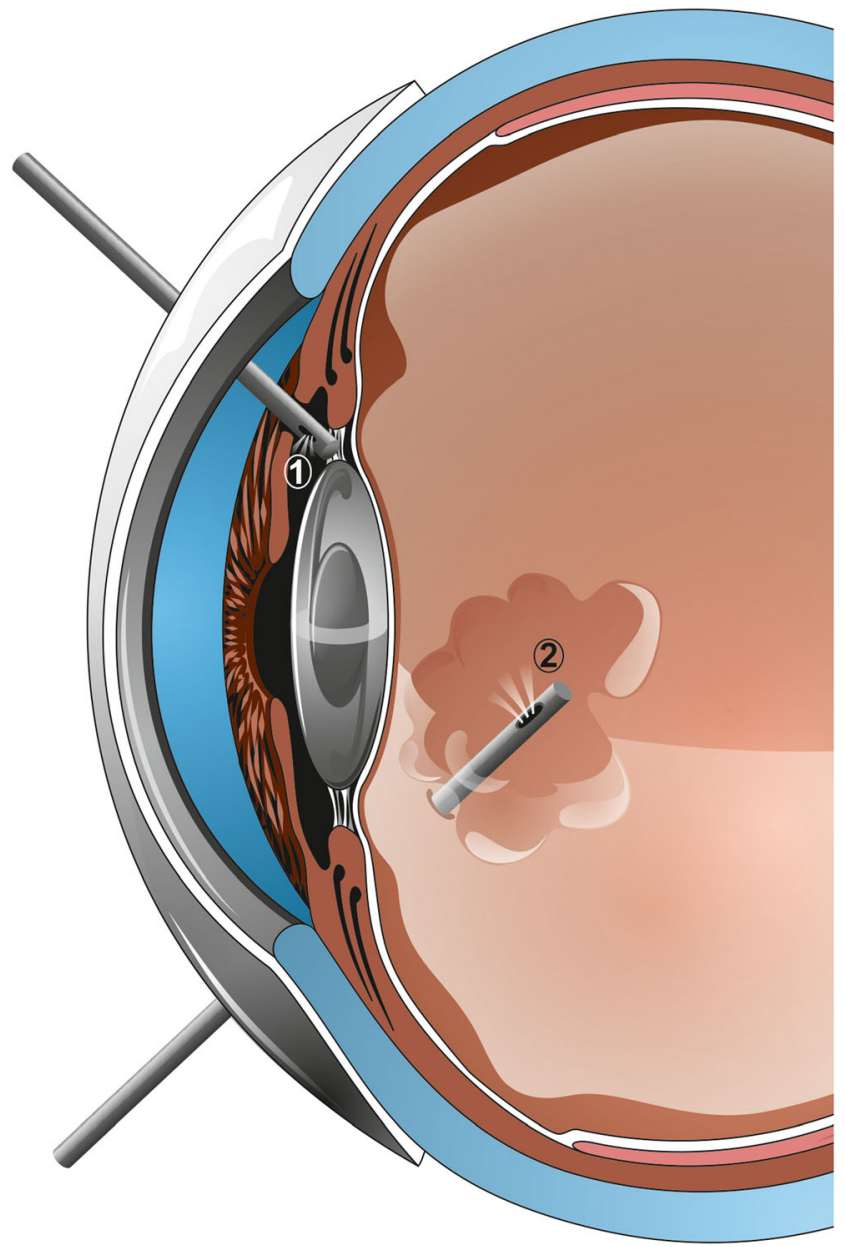

Fig. 2 Recommended method of treatment. Vitreous decompression should be performed, preferably with hyaloido-capsulo-iridectomy. This treatment can be achieved with an anterior (1) or posterior (2) approach. In phakic eyes, concomitant cataract extraction would be desired chamber approach, through a tunnel within the iridectomy. It has been emphasized that this procedure is safer, as the iridectomy is done within visual sight, in contrast to a blind approach through the pars plana. The initial results of such a procedure are good, though recurrence might occur in up to $40 \%$ of cases. The reason is blockage of the channel by vitreous or fibrin [17]. In a recent Saudi Arabian study, the efficacy of vitrectomy combined with hyaloido-capsulo-iridectomy has been confirmed on a group of 69 eyes. A two-port pars plana vitrectomy with surgical microscope lighting can be as effective as a 3-port procedure [31]. Some authors underline that the removal of the anterior hyaloid face with capsulectomy is the key to resolving the symptoms of fluid misdirection syndrome, rather than debulking the vitreous [11, 31, 53]. Furthermore, small-gauge techniques might be as efficient as traditional 20-gauge vitrectomy [11].

Most of the cases described in literature do relate to pseudophakic eyes. If malignant glaucoma develops in a phakic eye most authors recommend concomitant vitrectomy and cataract extraction [10,33]. Harbor et al. stress that lensectomy may be considered in eyes with substantial corneal edema or dense cataract, or when the anterior chamber does not deepen during vitrectomy [37]. Tsai et al. [33] reported better surgical outcome if an additional posterior capsulectomy was performed. Sharma et al. [10] suggest performing vitrectomy to reduce posterior pressure, followed by phacoemulsification and subsidiary vitrectomy followed by zonulo-hyaloidectomy. Chaundry et al. [54] claim that if one eye develops aqueous misdirection after surgery, prophylactic pars plana vitrectomy during cataract surgery of the contralateral eye may be beneficial.

\section{Conclusion}

The fluid misdirection syndrome is a rare clinical condition characterized by an axially very shallow anterior chamber with the absence of suprachoroidal effusion or hemorrhage and no noticeable pathology of the iris-lens diaphragm. In all of the described cases, fluid becomes entrapped in PC. The positive pressure of the vitreous chamber does move the lens-iris diaphragm frontally, leading to angle closure and restricting spontaneous resolution. Hyperopia and lax zonular fibers/pseudoexfoliation can increase the risk for developing this syndrome. Furthermore, after an episode of malignant glaucoma in one eye, there is a high risk of a malignant course at the time of surgery or in the postoperative period [55]. This proves that all these disorders should be treated as one nosological syndrome.

We suggest the term acute fluid misdirection syndrome for the cascade of events during phacoemulsification surgery. The pathophysiology of acute fluid misdirection syndrome is based on inappropriate movement of balanced salt solution via the zonular fibers. This definitely better describes the 
nature of the syndrome rather than one of its signs. With that, understanding the pathophysiology will lead to unconditional and thought-out sorting out of the intervention.

We believe chronic fluid misdirection syndrome better describes the nature of malignant glaucoma. It is based on similar mechanisms of cilio-lenticular block of aqueous flow leading to the misdirection of aqueous posteriorly into or beside the vitreous gel, leading to the characteristic diffuse shallowing of the anterior chamber accompanied by a precipitous rise in intraocular pressure. It might seem unreasonable to consider malignant glaucoma a chronic process as, clinically, the marked increase of intraocular pressure occurs with some rapidity. However, it does occur gradually. The first symptom is often an improvement in near vision secondary to a myopic shift in refraction as the lens-iris diaphragm moves forward [16]. Furthermore, the inappropriate movement of aqueous and anterior chamber shallowing might be observed several days prior to intraocular pressure elevation. Therefore, malignant glaucoma can be difficult to detect early in its course before elevation in IOP occurs. The prognosis of this condition is good with currently available treatment modalities, and "malignant glaucoma" no longer deserves its historical name. It should be emphasized that using the current term leads to misunderstanding. It is necessary to explain to patients with malignant glaucoma that the term does not indicate a neoplastic process, and that glaucomatous damage to the optic disc is not always a consequence of the condition.

It is anticipated that using a clearly specified definition of fluid misdirection syndrome will enhance the validity of published data, assist in the identification of risk factors, and make it possible to establish an unified effective treatment for this dangerous condition.

Acknowledgements Authors thank Dr. Tetsuro Oshika from the Department of Ophthalmology, University of Tsukuba, Tsukuba, Japan and Dr. Anders Behndig from the Department of Clinical Sciences/ Ophthalmology, Umeå University, Umeå, Sweden for the critical discussion of our work.

Funding This study was partially funded by the Institute for Research in Ophthalmology, Foundation for Ophthalmology Development, Poznan, Poland. The sponsor had no role in the design or conduct of this research.

Compliance with ethical standards All authors certify that they have no affiliations with or involvement in any organization or entity with any financial interest (such as honoraria; educational grants; participation in speakers' bureaus; membership, employment, consultancies, stock ownership, or other equity interest; and expert testimony or patent-licensing arrangements), or non-financial interest (such as personal or professional relationships, affiliations, knowledge, or beliefs) in the subject matter or materials discussed in this manuscript.

For this type of study formal consent was not rerequired.

Dr. Grzybowski reports grants, personal fees and non-financial support from Bayer, non-financial support from Novartis, non-financial support from Alcon, non-financial support from Thea, personal fees and nonfinancial support from Valeant, non-financial support from Santen, outside the submitted work.
Open Access This article is distributed under the terms of the Creative Commons Attribution 4.0 International License (http:// creativecommons.org/licenses/by/4.0/), which permits unrestricted use, distribution, and reproduction in any medium, provided you give appropriate credit to the original author(s) and the source, provide a link to the Creative Commons license, and indicate if changes were made.

\section{References}

1. Graefe A (1869) Beiträge zur Pathologie und Therapie des Glaucoms. Albrecht von Graefes Archiv für Ophthalmologie 15: $108-252$

2. Kam AW, Chen TS, Wang SB, Jain NS, Goh AY, Douglas CP, McKelvie PA, Agar A, Osher RH, Francis IC (2016) Materials in the vitreous demonstrated under the operating microscope during cataract surgery and confirmed histologically. Clin Exp Ophthalmol. https://doi.org/10.1111/ceo.12818

3. Lau OCF, Montfort JM, Sim BWC, Lim CHL, Chen TSC, Ruan CW, Agar A, Francis IC (2014) Acute intraoperative rock-hard eye syndrome and its management. J Cataract Refract Surg 40:799-804

4. Mackool RJ, Sirota M (1993) Infusion misdirection syndrome. J Cataract Refract Surg 19:671-672

5. Olson RJ, Younger KM, Crandall AS, Mamalis N (1994) Subcapsular fluid entrapment in extracapsular cataract surgery. Ophthalmic Surg 25:688-689

6. Dewey SH (2011) "Please give me another chance. Intraoperative fluid misdirection associated with unexpected coughing," presented at the annual meeting of the American Academy of Ophthalmology, Orlando, Florida, USA, October 2011. Syllabus, pp 109-110. http:// www.aao.org/pdf/Refractive-Surgery-2011-Syllabus.pdf. Accessed 8 Aug 2014

7. Grzybowski A, Prasad S (2014) Acute aqueous misdirection syndrome: pathophysiology and management. J Cataract Refract Surg 40:2167

8. Wu Z-H, Wang Y-H, Liu Y (2016) Management strategies in malignant glaucoma secondary to antiglaucoma surgery. Int $\mathrm{J}$ Ophthalmol 9:63-68

9. Little BC, Hitchings RA (1993) Pseudophakic malignant glaucoma: Nd:YAG capsulotomy as a primary treatment. Eye 7(Pt 1):102104

10. Sharma A, Sii F, Shah P, Kirkby GR (2006) Vitrectomyphacoemulsification-vitrectomy for the management of aqueous misdirection syndromes in phakic eyes. Ophthalmology 113: 1968-1973

11. Meng L, Wei W, Li Y, Hui X, Han X, Shi X (2015) 25-gauge pars plana vitrectomy for ciliary block (malignant) glaucoma. Int Ophthalmol 35:487-493

12. Rękas M, Krix-Jachym K, Żarnowski T (2015) Evaluation of the effectiveness of surgical treatment of malignant glaucoma in pseudophakic eyes through partial PPV with establishment of communication between the anterior chamber and the vitreous cavity. J Ophthalmol 2015:873124

13. Premsenthil M, Salowi MA, Siew CM, ak Gudom I, Kah T (2012) Spontaneous malignant glaucoma in a patient with patent peripheral iridotomy. BMC Ophthalmol 12:64

14. Pasaoglu IB, Altan C, Bayraktar S, Satana B, Basarir B (2012) Surgical management of pseudophakic malignant glaucoma via anterior segment-peripheral iridectomy capsulo-hyaloidectomy and anterior vitrectomy. Case Rep Ophthalmol Med 2012:794938. https://doi.org/10.1155/2012/794938

15. Zarnowski T, Rękas M (2014) Efficacy and safety of a new surgical method to treat malignant glaucoma in pseudophakia: reply. Eye 28:1391-1392 
16. Shahid H, Salmon JF (2012) Malignant glaucoma: a review of the modern literature. J Ophthalmol 2012:1-6

17. Madgula IM, Anand N (2014) Long-term follow-up of zonulohyaloido-vitrectomy for pseudophakic malignant glaucoma. Indian J Ophthalmol 62:1115-1120

18. Lois N, Wong D, Groenewald C (2001) New surgical approach in the management of pseudophakic malignant glaucoma. Ophthalmology 108:780-783

19. Varma DK, Belovay GW, Tam DY, Ahmed IIK (2014) Malignant glaucoma after cataract surgery. J Cataract Refract Surg 40:18431849

20. Dave P, Senthil S, Rao HL, Garudadri CS (2013) Treatment outcomes in malignant glaucoma. Ophthalmology 120:984-990

21. Stumpf TH, Austin M, Bloom PA, McNaught A, Morgan JE (2008) Transscleral cyclodiode laser photocoagulation in the treatment of aqueous misdirection syndrome. Ophthalmology 115:2058-2061

22. Heindl LM, Koch KR, Cursiefen C, Konen W (2013) Optical coherence tomography and ultrasound biomicroscopy in the management of pseudophakic malignant glaucoma. Graefes Arch Clin Exp Ophthalmol 251:2261-2263

23. Prata TS, Dorairaj S, De Moraes CGV, Mehta S, Sbeity Z, Tello C, Liebmann J, Ritch R (2013) Is preoperative ciliary body and iris anatomical configuration a predictor of malignant glaucoma development? Clin Exp Ophthalmol 41:541-545

24. Debrouwere V, Stalmans P, Van Calster J, Spileers W, Zeyen T, Stalmans I (2012) Outcomes of different management options for malignant glaucoma: a retrospective study. Graefes Arch Clin Exp Ophthalmol 250:131-141

25. Arya SK, Sonika KS, Kumar S, Kang M, Sood S (2004) Malignant glaucoma as a complication of Nd:YAG laser posterior capsulotomy. Ophthalmic Surg Lasers Imaging 35:248-250

26. Brooks AM, Harper CA, Gillies WE (1989) Occurrence of malignant glaucoma after laser iridotomy. Br J Ophthalmol 73:617-620

27. Lazar M, Godel V (1981) Anterior pupillary block. Acta Ophthalmol 59:221-224

28. Ozeki N, Yuki K, Kimura I (2010) Alternative approach to treating malignant glaucoma after trabeculectomy with unplanned zonulectomy. Clin Ophthalmol 4:383-385

29. Massicotte EC, Schuman JS (1999) A malignant glaucoma-like syndrome following pars plana vitrectomy. Ophthalmology 106: 1375-1379

30. Francis BA, Babel D (2000) Malignant glaucoma (aqueous misdirection) after pars plana vitrectomy. Ophthalmology 107:1220 1222

31. Al Bin Ali GY, Al-Mahmood AM, Khandekar R, Abboud EB, Edward DP, Kozak I (2017) Outcomes of pars plana vitrectomy in the management of refractory aqueous misdirection syndrome. Retina 37:1916-1922

32. Bitrian E, Caprioli J (2010) Pars plana anterior vitrectomy, hyaloido-zonulectomy, and iridectomy for aqueous humor misdirection. Am J Ophthalmol 150:82-87.e1

33. Tsai JC, Barton KA, Miller MH, Khaw PT, Hitchings RA (1997) Surgical results in malignant glaucoma refractory to medical or laser therapy. Eye 11(Pt 5):677-681

34. Greenfield DS, Tello C, Budenz DL, Liebmann JM, Ritch R (1999) Aqueous misdirection after glaucoma drainage device implantation. Ophthalmology 106:1035-1040

35. Lynch MG, Brown RH, Michels RG, Pollack IP, Stark WJ (1986) Surgical vitrectomy for pseudophakic malignant glaucoma. Am J Ophthalmol 102:149-153

36. Tomey KF, Senft SH, Antonios SR, Shammas IV, Shihab ZM, Traverso CE (1987) Aqueous misdirection and flat chamber after posterior chamber implants with and without trabeculectomy. Arch Ophthalmol 105:770-773
37. Harbour JW, Rubsamen PE, Palmberg P (1996) Pars plana vitrectomy in the management of phakic and pseudophakic malignant glaucoma. Arch Ophthalmol 114:1073-1078

38. Kawasaki S, Suzuki T, Yamaguchi M, Tasaka Y, Shiraishi A, Uno T, Sadamoto M, Minami N, Naganobu K, Ohashi Y (2009) Disruption of the posterior chamber-anterior hyaloid membrane barrier during phacoemulsification and aspiration as revealed by contrast-enhanced magnetic resonance imaging. Arch Ophthalmol 127:465-470

39. Kawasaki S, Tasaka Y, Suzuki T, Zheng X, Shiraishi A, Uno T, Ohashi Y (2011) Influence of elevated intraocular pressure on the posterior chamber-anterior hyaloid membrane barrier during cataract operations. Arch Ophthalmol 129:751-757

40. Mastropasqua L, Ciancaglini M, Carpineto P, Lobefalo L, Gallenga PE (1994) Aqueous misdirection syndrome: a complication of neodymium: YAG posterior capsulotomy. J Cataract Refract Surg 20: 563-565

41. Zacharia PT, Abboud EB (1998) Recalcitrant malignant glaucoma following pars plana vitrectomy, scleral buckle, and extracapsular cataract extraction with posterior chamber intraocular lens implantation. Ophthalmic Surg Lasers 29:323-327

42. Matlach J, Slobodda J, Grehn F, Klink T (2012) Pars plana vitrectomy for malignant glaucoma in nonglaucomatous and in filtered glaucomatous eyes. Clin Ophthalmol 6:1959-1966

43. de Preobrajensky N, Mrejen S, Adam R, Ayello-Scheer S, Gendron G, Rodallec T, Sahel J-A, Barale P-O (2010) 23-gauge transconjunctival sutureless vitrectomy: a retrospective study of 164 consecutive cases. J Fr Ophtalmol 33:99-104

44. Chandler PA (1951) Malignant glaucoma. Am J Ophthalmol 34: 993-1000

45. Kaushik S, Sachdev N, Pandav SS, Gupta A, Ram J (2006) Bilateral acute angle closure glaucoma as a presentation of isolated microspherophakia in an adult: case report. BMC Ophthalmol 6:29

46. Shaffer RN (1954) The role of vitreous detachment in aphakic and malignant glaucoma. Trans Am Acad Ophthalmol Otolaryngol 58: 217-231

47. Quigley HA, Friedman DS, Congdon NG (2003) Possible mechanisms of primary angle-closure and malignant glaucoma. J Glaucoma 12:167-180

48. Quigley HA (2009) Angle-closure glaucoma - simpler answers to complex mechanisms: LXVI Edward Jackson Memorial Lecture. Am J Ophthalmol 148:657.e1-669.e1

49. Fatt I (1977) Hydraulic flow conductivity of the vitreous gel. Invest Ophthalmol Vis Sci 16:565-568

50. Tello C, Chi T, Shepps G, Liebmann J, Ritch R (1993) Ultrasound biomicroscopy in pseudophakic malignant glaucoma. Ophthalmology 100:1330-1334

51. Scott AS, Smith VH (1961) Retrolental decompression for malignant glaucoma. Br J Ophthalmol 45:654-661

52. Zhou C, Qian S, Yao J, Tang Y, Qian J, Lu Y, Xu G, Sun X (2012) Clinical analysis of 50 Chinese patients with aqueous misdirection syndrome: a retrospective hospital-based study. J Int Med Res 40: 1568-1579

53. Byrnes GA, Leen MM, Wong TP, Benson WE (1995) Vitrectomy for ciliary block (malignant) glaucoma. Ophthalmology 102:13081311

54. Chaudhry NA, Flynn HW Jr, Murray TG, Nicholson D, Palmberg PF (2000) Pars plana vitrectomy during cataract surgery for prevention of aqueous misdirection in high-risk fellow eyes. Am J Ophthalmol 129:387-388

55. Simmons RJ (1972) Malignant glaucoma. Br J Ophthalmol 56: 263-272

56. Saunders PP, Douglas GR, Feldman F, Stein RM (1992) Bilateral malignant glaucoma. Can J Ophthalmol 27:19-21 